\title{
Simulations geometric structures of the stepped profile bearing surface of the piston
}

\author{
Emil Wroblewski ${ }^{1, *}$, Antoni Iskra $^{1}$, and Maciej Babiak ${ }^{1}$ \\ ${ }^{1}$ Poznan University of Technology, Faculty of Machines and Transport, ul. Piotrowo 3, 60-965 Poznan, Poland
}

\begin{abstract}
The main node piston-pin-piston rings are most responsible for the formation of mechanical losses. It is advisable to reduce friction losses in the piston-cylinder group lead to an increase in the overall efficiency of the engine and thus reduce the fuel consumption. The method to reduce the area covered by the oil film is a modification of the bearing surface of the piston by adjusting the profile. In this paper the results of simulation for the stepped microgeometry piston bearing surface are presented.
\end{abstract}

\section{Introduction}

The advancement of modern engines is chiefly aimed at environment protection and low fuel consumption [1-2]. To meet the above-mentioned criteria, engines are designed based on the idea of downsizing characterized by a reduction of their displacement and increasing their effective pressure by the application of a variety of supercharging systems [3]. The consequence of these changes is that engines operate at high thermal and mechanical loads. This is an adverse phenomenon for the piston-crankshaft assembly, particularly for pistons exposed to high temperatures and pressures inside the cylinder [4-6].

Modern engines are also expected to provide the highest overall efficiency [7]. The way to ensure that is to reduce the friction loss in the piston-cylinder pair [89]. Constructors aspire to design units, that have preserved its initial state in the longest possible time. In the case of combustion engines can be list a few groups, which consume deteriorating engine parameters and finally, makes it impossible to operation. They are mainly components of the piston-cylinder and crankshaft bearings [10-11].

The diagnostic testing of internal combustion engine can be made by using working processes and methods which take advantage of leftover processes. Working processes give information about general condition of internal combustion engine [12]. Leftover processes give information about condition of particular subassemblies and kinematic couples. This methods are based on analysis of vibrations and noise [13-14].

Over the years combustion engine's pistons changed their geometric proportions to a greater extent, but still their essential role is to close the variable volume combustion chamber. However performing of such main functionality is accompanied by a number of adverse effects, such as [15-16]:

- friction losses,
- forces and moments of inertia transferred to the motor suspension,

- lubricating oil consumption,

- noise emission.

The geometry of the gap between the bearing surface of the piston and the cylinder has large effect on friction losses. The area covered by the oil film contributes to these losses more than the thickness of the oil film. A method to reduce the coverage area of the oil film is to use different bearing surface shapes of the pistonstepped-like or barrel-like. Barrel-like shape is commonly used, but a stepped one was not yet applied for various reasons. The stepped shape can be obtained i.e. by the application of refining coatings of materials with good friction properties [17-19]. One such material is a graphite, commonly used to cover the bearing surface of the piston. Currently the entire bearing surfaces of the piston are coated. Such method produces different boundary friction conditions, but it does not affect the fluid friction formation significantly in the oil film [20-21].

The paper presents the results of simulation research for the reduction of frictional losses and wear of the bearing surface of the piston and the cylinder wall by covering the support surface of the piston with a layer of graphite in the H-shape. A stepped profile obtained this way is characterized by a beneficial tribological properties of the kinematic piston-cylinder system under fluid friction conditions. The solution proposed by the authors hereby extends the scope of tasks performed by the coatings on the bearing surface of the piston.

\section{The piston skirt}

Piston skirt is to ensure axial displacement of the piston inside the cylinder and a transfer of lateral forces on the cylinder liner.

In reality, however, the cooperation of the piston skirt with the cylinder occurs on a much smaller area,

* Corresponding author: emil.z.wroblewski@,doctorate.put.poznan.pl 
which results in a reduction of stresses between these surfaces. Taking this fact into account, it is easily observable that the piston skirt operates in much worse conditions than those of generously lubricated sliding bearings. The lubrication of the piston skirt is much scanter. Ensuring the required durability of the piston skirt under such conditions is a very difficult task requiring a careful selection of materials and design solutions [22].

The distribution of temperatures on the piston circumference is uneven. The presence of the kingpin hubs and parts connecting the hubs with the piston makes the cross-section of this spot greater than the rest of the circumference. Parts of greater cross-section have lower thermal resistance, which makes the temperature on the piston skirt in these regions much higher than on the plane perpendicular to the kingpin axis. This results in greater thermal deformations towards the kingpin axis, which is why the piston skirt must be oval with a high ovality axis perpendicular to the axis of the kingpin and a low ovality axis alongside the kingpin to ensure that under operating temperatures the piston skirt becomes cylinder-shaped or close to it [6].

The operating force acting on the piston influences not only the friction conditions between the piston and the cylinder liner but also deforms the piston skirt, which is why, when cold, the guiding element should be shaped in such a way as to ensure cooperation with the cylinder liner on the largest possible area upon thermal deformation under operating temperatures and under the influence of the lateral forces.

The above-mentioned factors render the geometry of the piston skirt very complex, particularly in engines of high displacement/power ratio. When the piston reaches its operating temperatures, the play between the piston and the cylinder liner changes. Changes in the play also occur after any change of the operating conditions following the stabilization of the thermal equilibrium $[6,22]$.

Such play variations are disadvantageous for a variety of reasons. One of them is the difficulty to ensure optimum play in terms of friction and lubrication under a sufficiently wide range of conditions. An increase in the play under lower operating temperatures results in an increase in dynamic forces exerted by the piston on the cylinder, vibration of the cylinder sleeve as well as engine noise and may lead to cavitation damage of cylinder liners in water-cooled engines.

The shape of the piston skirt in the axial crosssection, perpendicularly to the kingpin axis, and in the transverse cross-section should be designed in such a way as to ensure the maximum area of cooperation between the piston skirt and the cylinder liner under operating temperatures and under forces exerted on the piston skirt.

A modification of the geometry of the piston skirt consists in choosing such a shape of the surface that will ensure the continuity of the oil film during the piston reciprocating motion with a possibly low value of friction loss in the piston-cylinder pair.

The adopted microgeometry of the piston skirt is a result of a continuation of former research. The authors assume an application of a layer of graphite of the shape of letter $\mathrm{H}$ on the piston skirt. Thus obtained stepped profile is characterized by good tribological properties under liquid friction and, owing to the application of graphite, one can expect good properties under boundary friction.

In order to ascertain the friction loss in the piston cylinder pair, 3 variants of piston microgeometry have been developed as shown in Fig. 1.

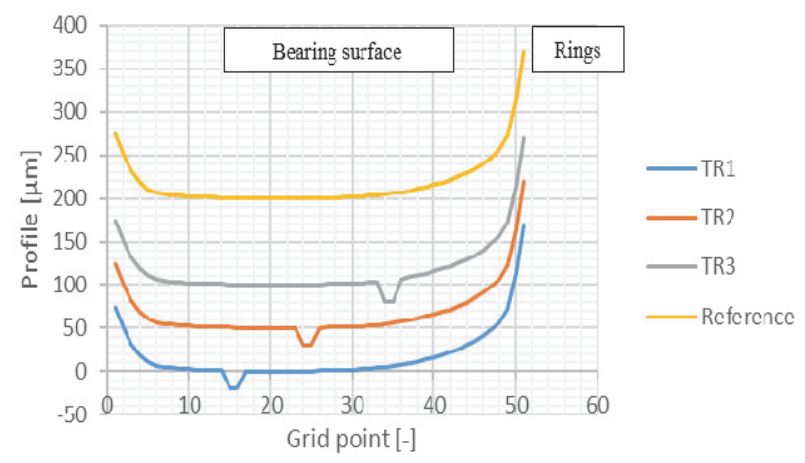

Fig. 1. Profile experimental piston TR1, TR2, TR3.

The horizontal bar of the letter $\mathrm{H}$ allows extending the area of high hydrodynamic pressure at the same time obtaining the effect of reduction of the oil film internal friction forces. Because the correctness of the computer model was validated experimentally in earlier research, the results confirm the positive results of the modification of the piston skirt microgeometry of a specified thickness of the $\mathrm{H}$ bar, which proves the validity of the replacement of classic barrel-shaped profile of the piston skirt with the stepped one by the application of a layer of graphite of a specified thickness.

\section{Simulation research results}

Calculations of oil film parameters were carried out for diverse profiles of piston skirt, beginning with barrel shape of standard pistons and ending with a stepped profile [23]. Figure 2 presents the course of oil film thickness with the thickest line, the thickness of oil layer over cylinder bore with the line of medium width and the friction force between piston skirt and bore with the thinnest line.

Most important parameters of engine operation for which the simulation has been carried out like:

om $=\omega-$ engine rotational speed,

eta $=\eta$ - engine oil viscosity,

eps $=\varepsilon-$ compression ratio,

$\mathrm{hr}-$ piston skit height,

$d u$ - piston nominal diameter

are presented over the draft.

At the upper right corner in Fig. 2. there is a schematic draft of piston skirt profile taken for calculations.

The calculations of the parameters of the oil film were performed for different microgeometries of the piston skirt, starting from the barrel-shaped profile of the reference pistons and ending with the stepped piston skirt profile. The thickness of the $\mathrm{H}$ bar is variable as 
well as its height in the bottom or top position against the symmetrical one.

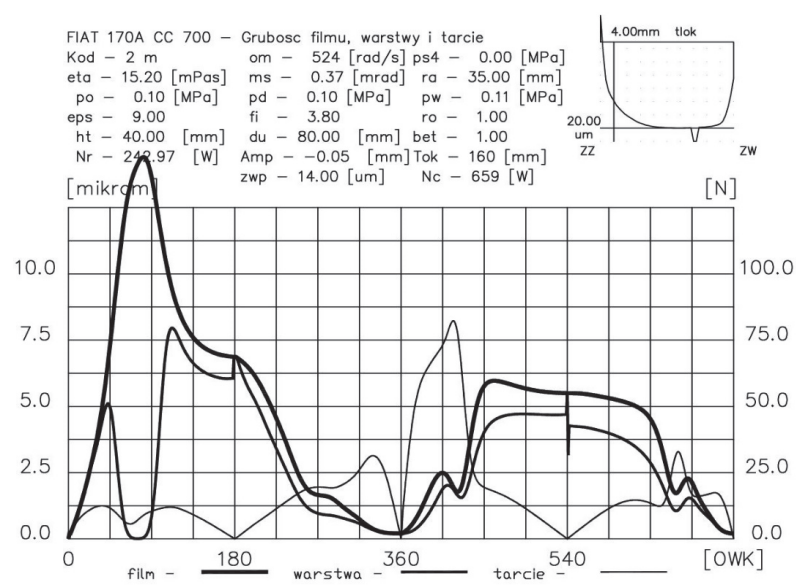

Fig. 2. Course of oil film thickness - the thickest line, thickness of oil layer over cylinder bore - line of medium width and friction force between piston skirt and bore - the thinnest line.

The calculation of oil film parameters were done using different geometry variants beginning from the stepped shape profile, and ending at barrel-like shape one. The analysis was conducted under the following conditions:

- engine revolution speed at $750 \mathrm{rpm}$ (idle) and 5000 rpm (full power),

- initial oil layer thickness at cylinder liner of 2 and $35 \mu \mathrm{m}$,

- $\quad$ pressure increase of $\varphi=2.13$ and 3.81,

- piston rings height: $1.5 ; 2 ; 4 \mathrm{~mm}$,

- piston height: $40 \mathrm{~mm}$,

- lubricating oil temperature of 60,80 and $100^{\circ} \mathrm{C}$,

- lubricating oil type of $10 \mathrm{~W} 30$.

Please note that the simulation was based on the theory of hydrodynamic lubrication and it does not take into account factors like i.e. tribological properties of materials working under boundary friction conditions. The simulations were aimed at defining the characteristics of a stepped profile under fluid friction conditions that prevail most of the time in the internal combustion engine.

The results of simulations are summarized in Fig. 3-6 obtained values are:

- $N r$ [W] - friction losses for piston bearing and cylinder surfaces,

- $\quad N c[\mathrm{~W}]$ - total friction losses for piston and piston rings system.

Research shows that all variants have brought the expected reduction in friction losses for the pistoncylinder system in relation to reference pistons.

As it turns out, the most advantageous solution is the symmetrical position of the horizontal $H$ bar, as the friction loss decreases by approx. $10 \%$ compared to pistons of a standard profile. One could also observe that the reduction in the friction loss is greater for higher engine speeds. This is an important observation because, due to increased friction loss converted into heat when increasing the engine speed, the engine elements warm up faster and the oil viscosity drops, which may lead to boundary friction. This phenomenon may reduce the friction loss assuming that boundary friction in the piston skirt - cylinder liner pair does not occur.

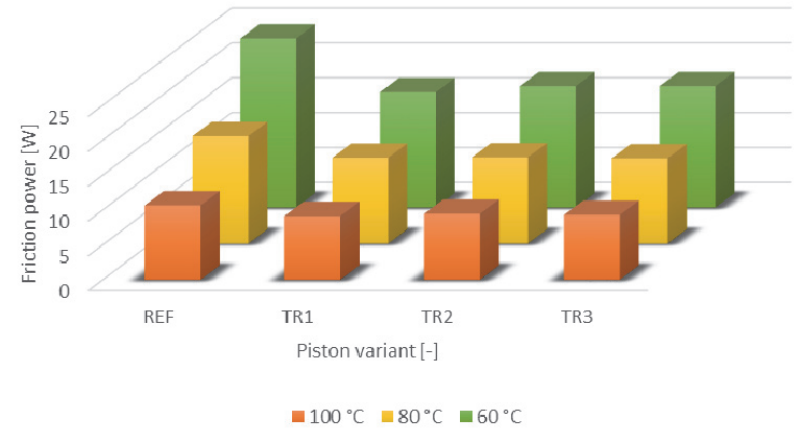

Fig. 3. Friction losses $-N r$ values, all pistons as a function of oil temperature - idle.

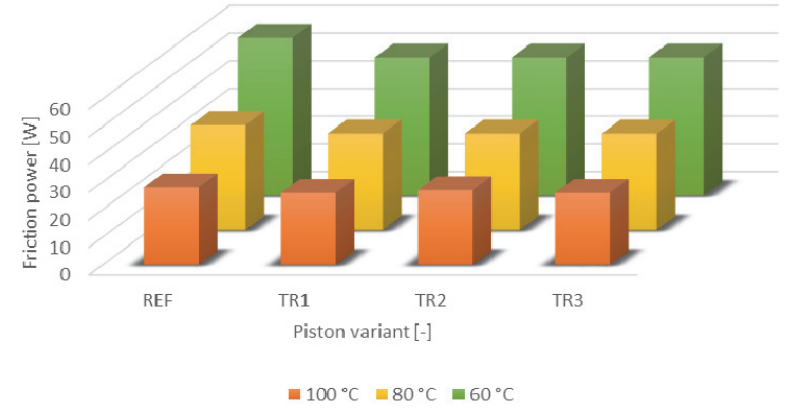

Fig. 4. Friction losses $-N c$ values, all pistons as a function of oil temperature - idle.

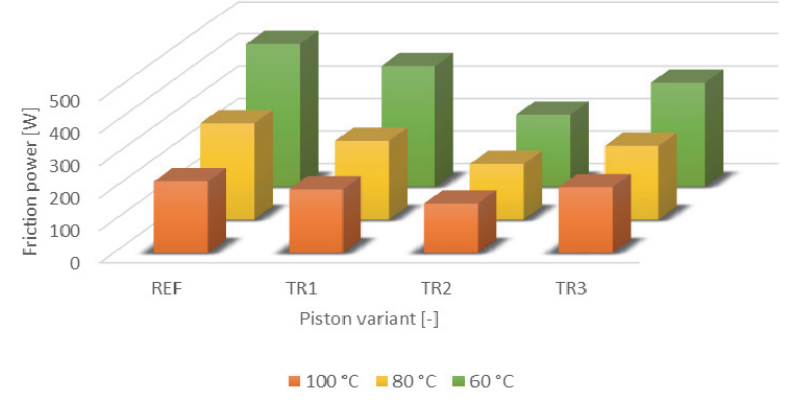

Fig. 5. Friction losses $-N r$ values, all pistons as a function of oil temperature - full power.

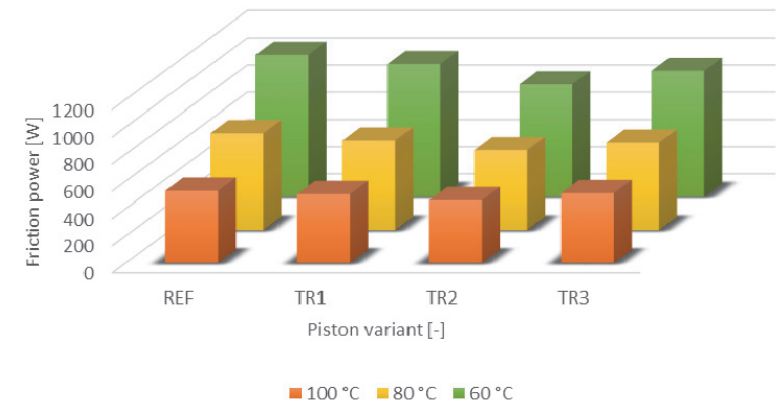

Fig. 6. Friction losses $-N c$ values, all pistons as a function of oil temperature - full power. 
a) Reference piston

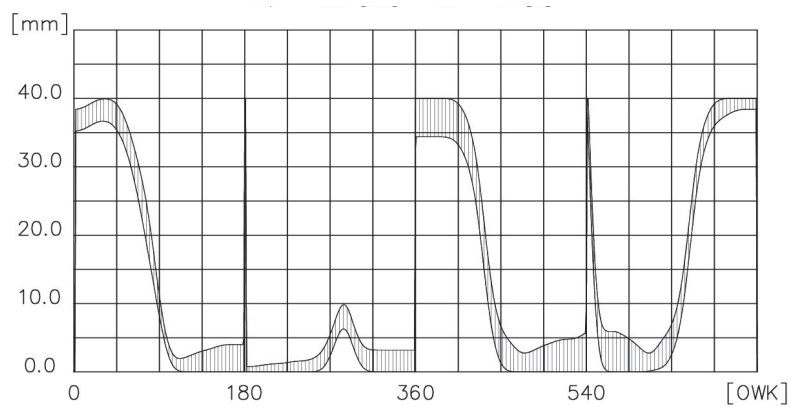

b) Piston variant TR1

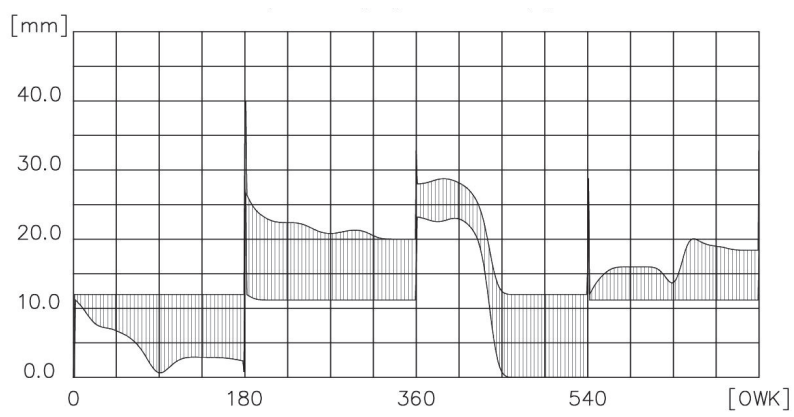

c) Piston variant TR2

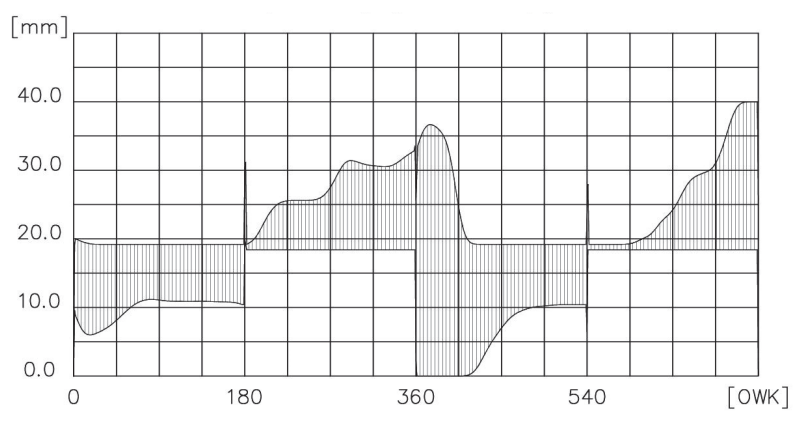

d) Piston variant TR3

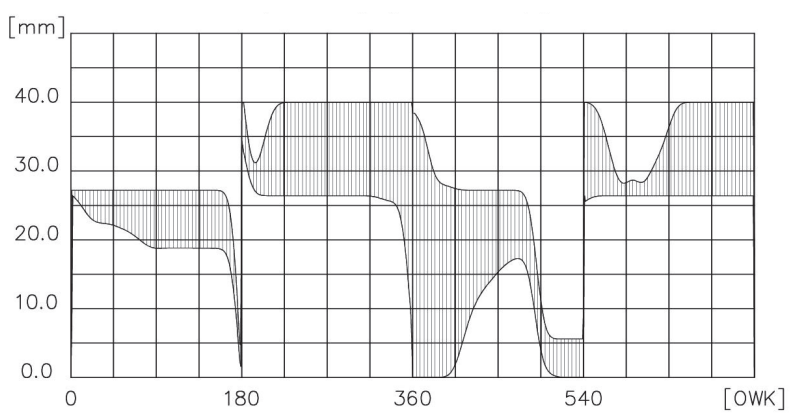

Fig. 7. Oil film height on the piston skirt - idle.

From the equations of hydrodynamic lubrication theory we know that in order to form a hydrodynamic oil film one needs a narrowing oil gap. As results from the performed simulations, the microgeometry of the piston skirt significantly influences the friction loss in the piston - cylinder pair. The obtained results are explained by the Fig. 7-8 presenting the coverage of the piston skirt with oil film.

Comparing the oil films on the piston skirts one can observe that intense oil film results in an increased friction loss. If the differences in the oil film level on the piston skirt are small, even minimum variations are impactful on the friction loss. The oil film thickness is greater for the stepped profile.

a) Reference piston

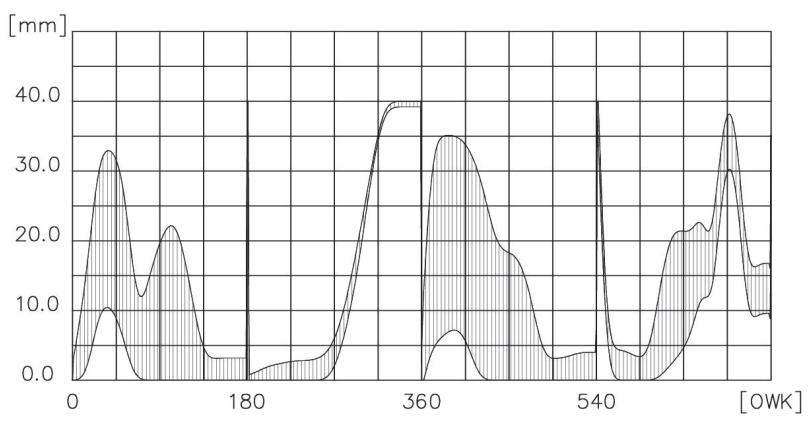

b) Piston variant TR1

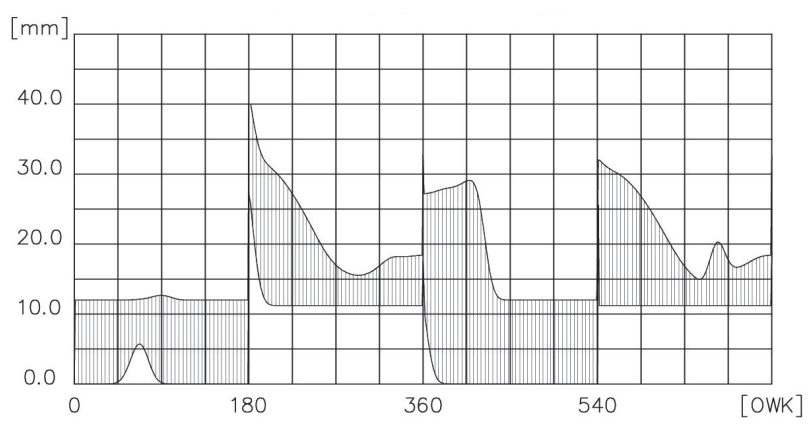

c) Piston variant TR2

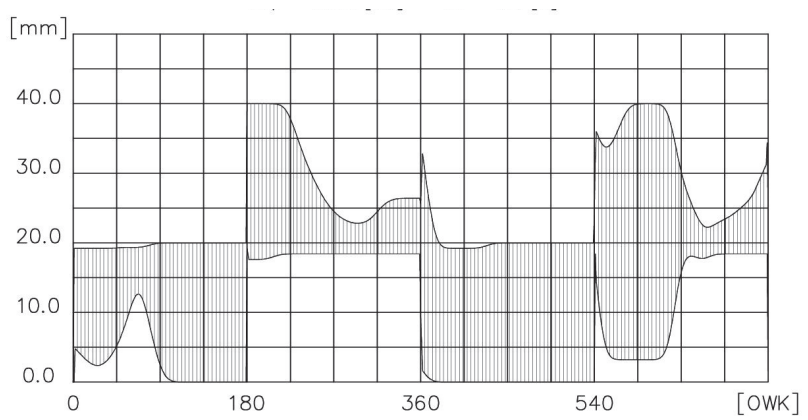

d) Piston variant TR3

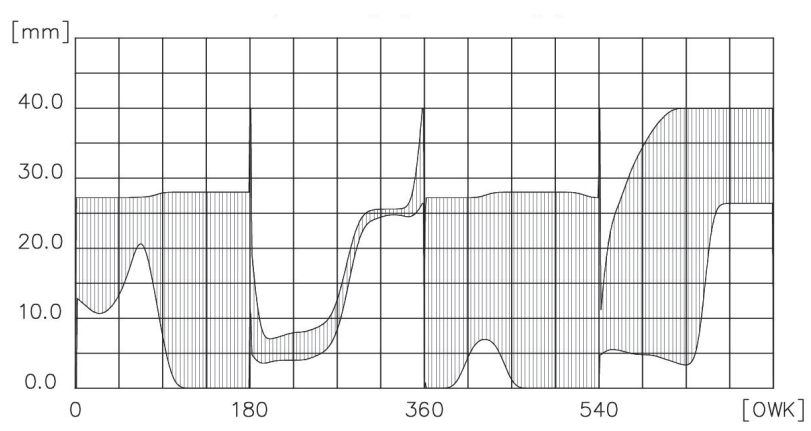

Fig. 8. Oil film height on the piston skirt - full power.

\section{Conclusions}

The results from the research allow to conclude that:

- friction losses can be reduced by configuring a gap between the piston and the cylinder to provide a continuous oil film separating the cooperating surfaces, 
- the results of the simulation showed that the stepped profile reduce friction loss by about $10 \%$ in relation to the barrel-like shape,

- surface coating of oil film reduces friction losses but does not eliminate them,

- viscosity forces perform a work that is immediately converted to heat, manifested by an increase in the temperature of the oil film layer forming the oil film,

- assessment of the oil film between the bearing surface of the piston and cylinder wall, must take into account the movement of the oil film layers, both in the direction of movement of the piston caused by the crank mechanism, and in the circumferential direction of the piston,

- slide promoting layers are especially desirable in conditions of permanent shortage of continuous oil film, for example after an engine longer stop and balance of its temperature with the ambient temperature,

- the stepped profile of the bearing surface increases the mechanical efficiency of the combustion engine and reduces fuel consumption,

- a stepped surface can be achieved by the coating of the support surface of the piston using lubricants like i.e. graphite.

The study presented in this article was performed within the statutory research (contract No. 05/52/DSPB/0262).

\section{References}

1. M. Blümm, A. Baberg, F. Dörnenburg, D. Leitzmann, MTZ 2 (2016)

2. J. Merkisz, P. Fuc, P. Lijewski, A. Ziolkowski, M. Galant, M. Siedlecki, Journal of Electronic Materials 45, 4028-4037 (2016), DOI: $10.1007 / \mathrm{s} 11664-016-4543-0$

3. J. Merkisz, P. Fuc, P. Lijewski, A. Ziolkowski, K.T. Wojciechowski, Journal of Electronic Materials 44, 1704-1715 (2015), DOI: 10.1007/s11664-014-3522-6

4. T. Deuss, H. Ehnis, R. Rose, R. Künzel, MTZ 5 (2010)

5. F. Dörnenburg, K. Lades, S. Kenningley, MTZ 4 (2010)

6. A. Iskra, M. Babiak, W. Wroblewski, IOP Conference Series-Materials Science and Engineering 148, UNSP 012068 (2016), DOI: 10.1088/1757-899X/148/1/012068

7. M. Fahr, W. Hanke, C. Klimesch, A. Rehl, MTZ 7-8 (2011)

8. M. Werkmann, A. Bitter, R. Künzel, MTZ 7-8 (2011)

9. G. Koszalka, Eksploatacja i Niezawodnosc Maintenance and Reliability 3, 40-44 (2011)

10. A. Baberg, M. Freidhager, H. Mergel, K. Schmidt, MTZ 12 (2012)

11. R. Backhaus, MTZ 12 (2009)
12. M. Orczyk, F. Tomaszewski, B. Czechyra, G.M. Szymanski, Proceedings of the International Congress on Sound and Vibration (Athens, 2016)

13. G.M. Szymanski, F. Tomaszewski, Proceedings of The 17th International Congress on Sound and Vibration (Cairo, 2010)

14. G.M. Szymanski, M. Josko, F. Tomaszewski, R. Filipiak, Mechanical Systems and Signal Processing 58-59, 298-307 (2015), 10.1016/j.ymssp.2014.12.017

15. R. Golloch, VDI Verlag 12 (Düsseldorf, 2001)

16. J. Merkisz, J. Mizera, M. Bajerlein, L. Rymaniak, P. Maj, Experimental and Applied Mechanics 518, 102-107 (2014), DOI: 10.4028/www.scientific.net/AMM.518.102

17. A. Iskra, M. Babiak, E. Wróblewski, Technika Transportu Szynowego 12, 644-647 (2015)

18. A. Iskra, M. Babiak, E. Wroblewski, Journal of KONES 22, 95-101 (2015)

19. A. Iskra, P. Krzymień, E. Wroblewski, Combustion Engines 162, 192-196 (2015)

20. T. Deuss, H. Ehnis, R. Rose, R. Künzel, MTZ 4 (2011)

21. R. Kuberczyk, J. Berner, M. Bargende, MTZ 1 (2009)

22. W. Kozaczewski, Konstrukcja grupy tłokowocylindrowej silników spalinowych (Warszawa, 2004)

23. A. Iskra, Studium konstrukcji $i$ funkcjonalności pierścieni $w$ grupie tłokowo-cylindrowej (Poznan, 1995) 